\title{
Mitral regurgitation: challenges and solutions
}

This article was published in the following Dove Press journal:

Research Reports in Clinical Cardiology

3 May 2016

Number of times this article has been viewed

Julius I Ejiofor

Lawrence Cohn ${ }^{\dagger}$

Tsuyoshi Kaneko

Division of Cardiac Surgery, Brigham and Women's Hospital, Boston, MA, USA

'Lawrence Cohn passed away on January 9,2016
Correspondence: Tsuyoshi Kaneko Division of Cardiac Surgery, Brigham and Women's Hospital, 75 Francis Street, Boston, MA 02II5, USA

Tel + I 6177326569

Fax + I 6177326559

Email tkaneko2@partners.org
Abstract: Since the first mitral valvuloplasty in 1923, the technique of mitral valvuloplasty has matured over the years and now has become the first-line treatment, especially in patients with myxomatous mitral regurgitation (MR). We have highlighted some of the major problems that are encountered with the various etiologies of MR. We believe that repair is always the optimal surgical procedure for any of the above etiologies if it is consistent with a long-term result. However, replacement has shown to be a safer procedure in some instances such as severe functional MR or destructive endocarditis.

Keywords: mitral regurgitation, mitral valvuloplasty, systolic anterior motion, functional mitral regurgitation, rheumatic valve disease

\section{Introduction}

The first mitral valve (MV) repair was performed at the Peter Bent Brigham Hospital in 1923. This was done on a 12-year-old girl with rheumatic mitral stenosis by Dr Elliot Cutler, who was the chief of cardiac surgery at the time. ${ }^{1}$ Since then, the technique of MV repair has matured over the years by numerous reports and now has become the first-line treatment especially in patients with myxomatous mitral regurgitation (MR). The techniques described by Duran et $\mathrm{al}^{2}$ and Carpentier et $\mathrm{al}^{3}$ still comprise the backbone of the repair strategies used even after 40 years. MV repair has proven to be superior even in elderly patients, ${ }^{4}$ and multiple minimally invasive strategies including small incision and robotic approach have been described. ${ }^{5-7}$

On the other hand, a certain subset of patients with MR poses a great challenge for clinicians. These include the optimal timing of the operation for MR, ischemic MR, functional MR, endocarditis, and systolic anterior motion (SAM) after MV repair. We will describe these challenges as well as the solutions in the current era.

\section{Timing of the operation in severe MR}

With the proven long-term success and durability of MV repair, the current (2014) American College of Cardiology/American Heart Association (ACC/AHA) guidelines offer a class I recommendation for MV repair in patients with severe symptomatic MR and asymptomatic MR with decreased left ventricular (LV) ejection fraction. ${ }^{8}$ However, debate still exists regarding the optimal timing of the operation in patients with severe asymptomatic MR with preserved LV function. Whether early surgical intervention in asymptomatic patients, before the onset of ventricular changes, improves outcomes of patients with chronic severe MR remains controversial. ${ }^{9-13}$ Proponents of early surgical 
repair argue that watchful waiting, until the development of symptoms or decreased left ejection fraction, increases the surgical risk and may be associated with increased long-term mortality and increased risk of heart failure. ${ }^{14,15}$

A recent retrospective analysis of 1,021 patients using the multinational Mitral Regurgitation International Database looked at this specific question. ${ }^{16}$ These patients had nonfunctional MR without class I indication for MV surgery. They were divided into 446 patients who underwent early surgery versus 575 who underwent medical management. Both with overall analysis and propensity-matched analysis, the early surgery group had significantly improved long-term survival and reduced incidence of postoperative heart failure.

Despite these studies, the current ACC/AHA guideline still places class IIa recommendation for asymptomatic patients with chronic severe primary MR with preserved LV function in whom the likelihood of a successful and durable repair without residual $\mathrm{MR}$ is $>95 \%$ with an expected mortality rate of $<1 \%$ when performed at a Heart Valve Center of Excellence. This recommendation may well change in the future with building evidence on early elective repair for asymptomatic severe MR. , $^{9} 10,13,17-19$

\section{Ischemic and functional MR}

Ischemic and functional MR is one of the most difficult conditions to treat because of the setting in which it occurs. There is usually severe LV dysfunction either from coronary artery disease or a primary cardiomyopathy. The progression of LV dysfunction may lead these patients to the transplant route if the MV regurgitation is not controlled early, as this contributes to further dilation and decreased LV function. Interestingly, though the MV is the focus of this problem the real pathology is the dilation of left ventricle causing annular dilation, not of the MV per se. The MV leaflets themselves are usually normal as are the papillary muscle and chordae in this situation. The main pathology is the enlarging left ventricle that is dilated, downward and outward, leading to separation of papillary muscles and non-tethering of the leaflets. All these contribute to severe MR. The MR thus makes the LV heart failure worse, leading to worse congestive heart failure.

So what is the solution to this problem? Many patients have progressed with these abnormalities and are heart transplant candidates or require LV assist devices because the failure progresses to an almost terminal state while the MV continues to leak. So early treatment of the MR may prolong a patient's life and prevent transplantation or at least postpone it considerably.
So what is the best surgical treatment for this abnormality of LV function which leads to severe MR? The operative therapy for this condition has fallen into three major categories. One of the most infrequent is a reparative procedure to the papillary muscles, so that they do not expand with the enlarging left ventricle and go down and out producing MR. Operations by Kron et al describe relocating the posterior papillary muscle to the mitral annulus. ${ }^{20}$ This restores the physiologic configuration of the subvalvular apparatus, and results in significantly reduced rates of recurrent $\mathrm{MR}$ and adverse cardiac events over time. However, there have been no published long-term results of this technique.

The most common therapy and one of the greatest debates in the field is downsizing an annular MV ring so as to cause cooptation in the MV leaflets. This has worked out in the short term, but many have been concerned about the long-term therapy as the ventricles continue to dilate and the papillary muscles go down and out from the original position, even through a small ring there may be a recurrence of MR. The final therapy is MV replacement which many cardiologists now advocate is a more definitive choice in this group so there would be no recurrence of MR and the MR would be totally obliterated by a prosthetic or bioprosthetic replacement device. Obviously, with this operation the papillary muscles and chordal attachment should be preserved as much as possible, both anterior and posterior leaflet to preserve the residual LV function after this operation. There has been an obvious reticence to advocate MV replacement for this device, although many cardiologists believe that the recurrence of the small annuloplasty ring operation has been deleterious. Clearly, MV repair, versus replacement, leads to better survival and fewer complications but with this particular disease the problem is which device to use.

A recently performed randomized control study gives further information to this debate. Acker et al randomized 251 patients with severe ischemic MR to MV repair and MV replacement. ${ }^{21}$ The results showed that the rate of mortality and LV reverse remodeling were similar. However, $32.6 \%$ in the MV repair group had recurrence of moderate or severe MR compared to $2.3 \%$ in MV replacement group. This is causing a shift toward more replacements than repairs in patients with severe functional MR.

Another recently performed randomized control study compared coronary artery bypass grafting versus coronary artery bypass grafting and MV repair in 301 patients with moderate functional MR. ${ }^{22}$ The results showed no difference in mortality and LV reverse remodeling. Addition of MV repair resulted in less moderate or severe MR, but longer 
cardiopulmonary bypass time, more neurological deficit, and longer hospital stay. At this point, MV repair for moderate functional MR does not seem to add any benefit.

\section{Rheumatic MV disease}

Rheumatic MV disease is a result of Streptococcus infection (rheumatic fever) triggered by autoimmune humoral and cellular responses. ${ }^{23}$ It remains the predominant heart valve disease in third world countries, ${ }^{23-26}$ while it is seldom seen in the United States and developed countries. ${ }^{23}$ Prior to widespread antibiotic use, rheumatic MV disease, mainly mitral stenosis or regurgitation, was very common in the United States. ${ }^{24}$ In fact, the previously mentioned first MV repair in 1923 at Brigham and Women's Hospital was for a rheumatic valve pathology which was successfully treated by commissurotomy. ${ }^{1}$

Mitral stenosis is the most common lesion seen in rheumatic heart disease, but it is often associated with rheumatic MR. It is unknown why rheumatic fever leads to valvular stenosis in some patients and pure regurgitation in others. In chronic rheumatic MR, the valves have diffuse fibrous thickening of the leaflets with minimal calcific deposits and relatively nonfused commissures; chordae tendineae usually are not extremely thickened or fused..$^{27-29}$ There also may be shortening of the chordae tendineae, fibrous infiltration of papillary muscle, and asymmetric annular dilatation in the posteromedial portion. ${ }^{30}$

Open mitral commissurotomy and subsequently balloon valvuloplasty has long been done for the stenotic, non-regurgitant rheumatic MV with excellent results, ${ }^{31-33}$ although the probability of a second valve operation as the stenotic MV becomes restenotic is very high. It should be noted that if the valve is severely calcified and there is obliteration of the subvalvular chordal structures by fibrosis, repair will be fruitless and replacement should be carried out. ${ }^{30}$ In rheumatic $\mathrm{MR}$, with preservation of the chordal structures and minimal calcification, satisfactory MV repair can be performed.

$\mathrm{MR}$ in this disorder may be improved once the leaflets are mobilized or if there are specific areas of calcification or fibrosis in the portion of the valve, particularly the anterior can be removed and a pericardial patch placed. Plastic repair operations done to the MV chordae and the papillary muscles have been accomplished with some degree of success, but the long-term success of MV reconstruction with mitral stenosis is the poorest of any of the etiologies in reducing and permanently obliterating the MR.

DiBandino et al reported their experience in 193 patients who underwent MV repair for rheumatic valve disease. ${ }^{34}$ The operative mortality was low at $0.5 \%$, but freedom from MV reoperation was $66 \%, 34 \%$, and $10 \%$ at 10,20 , and 30 years (Table 1). This was significantly lower than patients with myxomatous (freedom from reoperation $90 \%$ and $82 \%$ at 10 and 20 years) and functional (freedom from reoperation $63 \%$ at 10 years) etiology.

Thus, MV replacement in many countries is the first order of treatment rather than a commissurotomy because most natural history studies have shown a near certainty of reoperations. ${ }^{34-38}$ In places like Asia where there is a large population with rheumatic MV disease, they have opted, preferentially, to do an MV replacement so as to eliminate the possibility of a second operation in the near future. ${ }^{39}$

There are limited data comparing the late outcomes after MV repair versus replacement for rheumatic disease. A study by Yau et el looked at the results of 573 patients with rheumatic MV disease. ${ }^{40} \mathrm{MV}$ repair was done in $25 \%$ of the patients and after Cox proportional adjustment, operative mortality was better with repair $(0.7 \%$ after repair versus $5.1 \%$ for replacement) as was late survival. Valve-related complications were lower after repair, although late reoperations were higher. These data suggest a survival benefit of mitral repair for rheumatic disease, but at a higher reoperation rate. ${ }^{11,40}$

\section{Endocarditis}

Endocarditis of the MV is one of the devastating valvular complications that is universally fatal if untreated. Predisposing risk

Table I Criteria for determination of significant systolic anterior motion (SAM) potential

\begin{tabular}{ll}
\hline Assessment & Criteria \\
\hline TEE criteria & Prerepair SAM \\
& C-sept distance $\leq 25 \mathrm{~mm}$ \\
& Anterolateral A2 height - posteromedial \\
& A2 height $\geq 5 \mathrm{~mm}$ \\
Insertion location of A2 secondary chords & A2 override over the LVOT $>20 \%$ \\
Surgical assessment & Height of A2 from annulus to leaflet edge \\
& using modified Edwards mitral sizer, including \\
& assessment of asymmetry of lateral and medial \\
& portions of A2 \\
& After placement of annuloplasty band, \\
& remeasurement of A2 height to determine \\
& if $>7$ to 8 mm of anterior leaflet was below \\
& the coaptation line \\
& P2 height reducible to 10 mm \\
\hline
\end{tabular}

Notes: Reprinted from J Thorac Cardiovasc Surg. 146(4), Myers PO, Khalpey Z, Maloney AM, Brinster DR, D’Ambra MN, Cohn LH. Edge-to-edge repair for prevention and treatment of mitral valve systolic anterior motion, 836-840, @ 20I3, with permission from Elsevier. ${ }^{57}$

Abbreviations: TEE, transesophageal echocardiography; SAM, systolic anterior motion; C-sept, coaptation to septum; A2, middle scallop of the anterior mitral leaflet; LVOT, left ventricular outflow tract; P2, middle scallop of the posterior mitral leaflet. 
factors include intravascular drug abuse, immunosuppression, intravascular prosthesis and devices, hemodialysis catheters, and degenerative valvular diseases. Endocarditis of the native valve can present after dental work or minor surgery of any kind in someone with a slightly elongated or prolapsed valve. However, current ACC/AHA guidelines only recommend antimicrobial prophylaxis against bacterial endocarditis for patients with prior history of endocarditis, prosthetic heart valves, repaired and unrepaired cyanotic congenital heart disease, and valvular regurgitation in transplanted hearts. ${ }^{8,41}$

MV endocarditis usually presents as vegetations on the valve leaflets or ruptured chordae due to septic reasons. Endocarditis of the MV can also be repaired in many instances. Dreyfus et al demonstrated the feasibility of MR repair in patients with active endocarditis in $1990 .{ }^{42}$ They also introduced the concept of early surgery to prevent further destruction of the valve. ${ }^{11}$

Debridement of the valve is possible, but depending on the extent of structural damage, an annuloplasty ring is inserted. This is especially true, as most of these will occur in the setting of a prolapsed valve. There is obviously some concern in putting a prosthetic device into a septic area and many institutions have relied on a ring made of autologous pericardium which can accomplish the same function as a prosthetic ring in this situation preventing annular dilatation. In cases where the valve is irreparably damaged, then obviously debridement and valve replacement would be necessary. In many instances, there may be perforations of one leaflet or another which can be repaired with a pericardial patch or simple prolene suture.

Because of the extensive damage, replacement is more common in this etiology then repair, although repair should be striven for if one can accomplish the making of a competent MV once again.

Mihaljevic et al reported on a series of 53 patients with mitral endocarditis, only 21 underwent MV repair and others required MV replacement. ${ }^{43}$ Operative mortality was $0 \%$ in the MV repair group and $13 \%$ in the MV replacement group, which may reflect the sicker patient population with more extensive infection who underwent replacement.

\section{SAM after MV repair}

In patients with myxomatous $\mathrm{MR}$, a redundant anterior leaflet can obstruct the LV outflow tract (LVOT) after MV repair. This phenomenon is known as SAM, and occurs in $2 \%-14 \%$ of all MV repairs. ${ }^{44-46}$ SAM is caused by the mismatch between the mitral annular size and the mitral leaflet tissue present. Increased redundancy of the leaflet tissue is a risk factor with a small annuloplasty ring. After MV repair, if the line of leaflet coaptation is displaced anteriorly, then the anterior leaflet will be displaced into the LVOT. ${ }^{30,47,48}$ The two prominent mechanisms that describe SAM are "venturi effect" and the "drag effect," both of which describe the anterior leaflet obstructing the LVOT by pulling (venturi) or pushing (drag). ${ }^{49}$ When the LVOT contracts during systole, it pushes the mitral anterior leaflet into the LVOT, which creates a turbulence to pull on the anterior leaflet to cause MR.

In our institution, we use several algorithms to predict the possibility of SAM in patients undergoing MV repair. Any one of the following findings seen on preoperative transesophageal echocardiogram are considered high risk for SAM (Figure 1): interaction between the anterior leaflet and the subvalvular apparatus (coaptation-septal distance $\leq 25 \mathrm{~mm}$ ), asymmetrical middle scallop of the anterior mitral leaflet (A2) leaflet (lateral A2 height minus medial A2 height $\geq 5 \mathrm{~mm}$ ), insertion location of A2 chordae, and degree of override of the mitral annulus over LVOT. ${ }^{50,51}$

The typical cause of SAM after MV repair is inadequate resection of the leaflet and insertion of small ring. When the gradient across the valve is low (less than $40 \mathrm{mmHg}$ ), we treat this medically. A systematic approach to medically manage intraoperative post-MV repair SAM was proposed by Crescenzi et al. ${ }^{52,53}$ The first step is intravascular volume expansion and cessation of inotropes. If this fails, then beta-blockers are added and the aorta is manually compressed

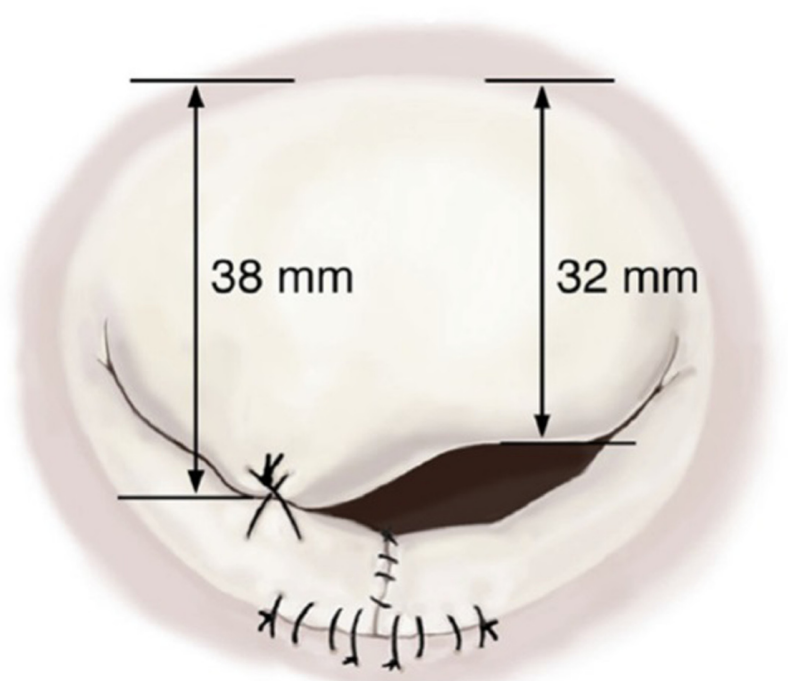

Figure I Edge-to-edge repair for prevention and treatment of mitral valve systolic anterior motion.

Notes: Reprinted from J Thorac Cardiovasc Surg. 146(4), Myers PO, Khalpey Z, Maloney AM, Brinster DR, D'Ambra MN, Cohn LH. Edge-to-edge repair for prevention and treatment of mitral valve systolic anterior motion, 836-840, (c) 20I3, with permission from Elsevier. ${ }^{57}$ 
for 30 seconds. If both these maneuvers fail and SAM persists, then the decision to go back to cardiopulmonary bypass has to be made for surgical re-repair. The majority of patients who developed SAM are successfully managed with medical therapy ${ }^{45,53}$ However, in $2 \%-8 \%$ of patients with SAM re-repair of the valve is required. ${ }^{45,54}$

Several studies have verified that conservative medical treatment of SAM after MV repair is associated with relatively good long-term results. ${ }^{44,45,54,55}$ In the recent study by Kuperstein et al, ${ }^{55} 40$ patients with post-MV repair SAM were followed for 54 months with both regular and exercise stress echocardiography. Freedom from reoperation due to SAM was $100 \%$ and there was no significant difference in the prevalence of advanced New York Heart Association functional class or significant recurrent MR between patients who presented with or without SAM during surgery. ${ }^{55}$

Traditionally, the re-repair is done by creating the posterior leaflet height low so that the coaptation point will move away from the septum, and placing a larger ring. However, there are situations where all this is done and you still see a gradient through the valve. In these difficult cases, we have used the edge-to-edge technique first described by Maisano et al. ${ }^{56}$ This was traditionally used as one of the repair techniques for MV

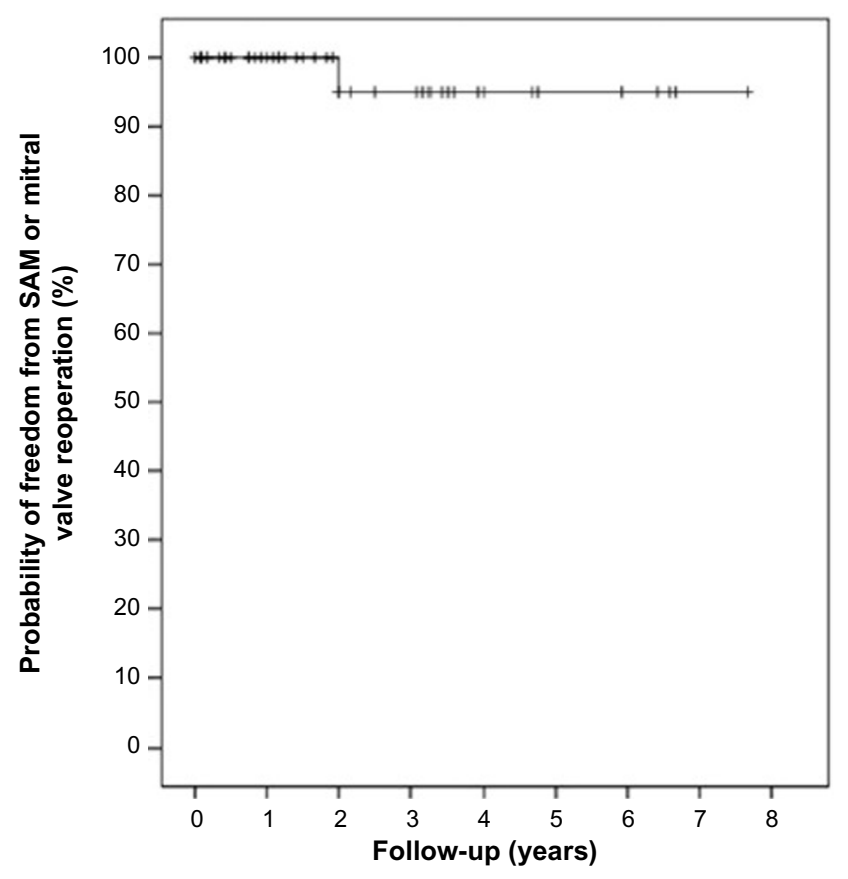

Figure 2 Kaplan-Meier analysis of freedom from systolic anterior motion and reoperation after edge-to-edge repair.

Notes: Reprinted from J Thorac Cardiovasc Surg. 146(4), Myers PO, Khalpey Z, Maloney AM, Brinster DR, D'Ambra MN, Cohn LH. Edge-to-edge repair for prevention and treatment of mitral valve systolic anterior motion, 836-840, (C) 2013, with permission from Elsevier. ${ }^{57}$

Abbreviation: SAM, systolic anterior motion.

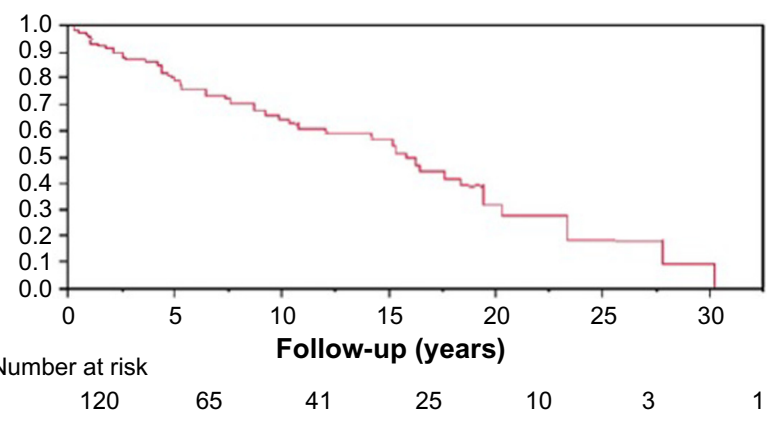

Figure 3 Kaplan-Meier analysis of freedom from reoperation in patients with rheumatic mitral disease.

Notes: Reprinted from J Thorac Cardiovasc Surg. 139(I), DiBardino DJ, ElBardissi AW, McClure RS, Razo-Vasquez OA, Kelly NE, Cohn LH. Four decades of experience with mitral valve repair: Analysis of differential indications, technical evolution, and long-term outcome. 76-84 (c) 2010, with permission from Elsevier. ${ }^{34}$

repair. However, we have utilized it in high SAM potential cases and patients who have SAM after the initial repair. The repair stitch is placed in the anterior mitral leaflet in the LVOT at the coaptation point of 22 and middle scallop of the posterior mitral leaflet. Each of the two residual orifice areas need to be $>2 \mathrm{~cm}^{2}$, to avoid mitral stenosis. The suture can be in the midline or offset if the leaflet was asymmetrical (Figure 2).

Myers et al reported the outcome of 65 edge-to-edge repairs used for high SAM potential and SAM after repair. ${ }^{57}$ There was zero operative mortality, zero postoperative MR, and no reoperation for SAM. During 26 months follow-up, only one patient presented with recurrent SAM which was managed medically. No patient had mitral stenosis (Figure 3). We believe that the edge-to-edge repair in high risk SAM cases is a simple and effective method.

\section{Conclusion}

We have highlighted some of the major problems that are encountered with the various etiologies of MR. Based on available evidence, we believe that MV repair is the optimal surgical procedure for the majority of the above etiologies if it is at all feasible. However, replacement has been shown to be a safer procedure in some instances such as severe functional MR or destructive endocarditis. In good hands, in major MV repair centers, mortality is extremely low, less than $1 \%$ and the probability of repair even in the most difficult etiology is better than $90 \%$ and should be even better in the coming years as better rings and more knowledge of the long-term results of these operations are documented.

\section{Disclosure}

The authors have nothing to disclose and have no conflict of interest. 


\section{References}

1. Cutler EC, Levine SA. Cardiotomy and Valvulotomy for Mitral Stenosis; Experimental Observations and Clinical Notes Concerning an Operated Case with Recovery. The Boston Medical and Surgical Journal. 1923;188(26):1023-1027.

2. Duran CG, Pomar JL, Revuelta JM, et al. Conservative operation for mitral insufficiency: critical analysis supported by postoperative hemodynamic studies of 72 patients. J Thorac Cardiovasc Surg. 1980;79(3):326-337.

3. Carpentier A, Deloche A, Dauptain J, et al. A new reconstructive operation for correction of mitral and tricuspid insufficiency. J Thorac Cardiovasc Surg. 1971;61(1):1-13.

4. Gaur P, Kaneko T, McGurk S, Rawn JD, Maloney A, Cohn LH. Mitral valve repair versus replacement in the elderly: Short-term and longterm outcomes. The Journal of Thoracic and Cardiovascular Surgery. 2014;148(4):1400-1406.

5. Cohn LH, Adams DH, Couper GS, et al. Minimally Invasive Cardiac Valve Surgery Improves Patient Satisfaction While Reducing Costs of Cardiac Valve Replacement and Repair. Annals of Surgery. 1997;226(4):421-428.

6. Navia JL, Cosgrove DM. Minimally invasive mitral valve operations. The Annals of Thoracic Surgery. 1996;62(5):1542-1544.

7. Chitwood WR, Elbeery JR, Moran JF. Minimally invasive mitral valve repair using transthoracic aortic occlusion. The Annals of Thoracic Surgery. 1997;63(5):1477-1479.

8. Nishimura RA, Otto CM, Bonow RO, et al. 2014 AHA/ACC Guideline for the Management of Patients With Valvular Heart Disease: A Report of the American College of Cardiology/American Heart Association Task Force on Practice Guidelines. Circulation. 2014;129(23):e521-e643.

9. Enriquez-Sarano M, Avierinos JF, Messika-Zeitoun D, et al. Quantitative determinants of the outcome of asymptomatic mitral regurgitation. N Engl J Med. 2005;352(9):875-883.

10. Kang DH, Kim JH, Rim JH, et al. Comparison of early surgery versus conventional treatment in asymptomatic severe mitral regurgitation. Circulation. 2009;119(6):797-804.

11. Madesis A, Tsakiridis K, Zarogoulidis P, et al. Review of mitral valve insufficiency: repair or replacement. Journal of thoracic disease . 2014;6 (Suppl 1):S39-S51.

12. Montant P, Chenot F, Robert A, et al. Long-term survival in asymptomatic patients with severe degenerative mitral regurgitation: a propensity score-based comparison between an early surgical strategy and a conservative treatment approach. J Thorac Cardiovasc Surg. 2009;138(6):1339-1348.

13. Rosenhek R, Rader F, Klaar U, et al. Outcome of watchful waiting in asymptomatic severe mitral regurgitation. Circulation. 2006;113(18):2238-2244.

14. Enriquez-Sarano M, Sundt TM. Early Surgery Is Recommended for Mitral Regurgitation. Circulation. 2010;121(6):804-812.

15. Gillinov AM, Mihaljevic T, Blackstone EH, et al. Should Patients With Severe Degenerative Mitral Regurgitation Delay Surgery Until Symptoms Develop? The Annals of Thoracic Surgery. 2010;90(2):481-488.

16. Suri RM, Vanoverschelde JL, Grigioni F, et al. Association Between Early Surgical Intervention vs Watchful Waiting and Outcomes for Mitral Regurgitation Due to Flail Mitral Valve Leaflets. JAMA. 2013;310(6):609.

17. Adams DH, Anyanwu AC. Valve Disease: Asymptomatic mitral regurgitation: does surgery save lives? Nat Rev Cardiol. Vol 6. England 2009:330-332.

18. Detaint D, Iung B, Lepage L, et al. Management of asymptomatic patients with severe non-ischaemic mitral regurgitation. Are practices consistent with guidelines? Eur J Cardiothorac Surg. 2008;34(5):937-942.

19. Schaff HV. Asymptomatic severe mitral valve regurgitation: observation or operation? Circulation. Vol 119. United States 2009:768-769.

20. Kron IL, Green GR, Cope JT. Surgical relocation of the posterior papillary muscle in chronic ischemic mitral regurgitation. The Annals of Thoracic Surgery. 2002;74(2):600-601.
21. Acker MA, Parides MK, Perrault LP, et al. Mitral-Valve Repair versus Replacement for Severe Ischemic Mitral Regurgitation. New England Journal of Medicine. 2014;370(1):23-32.

22. Smith PK, Puskas JD, Ascheim DD, et al. Surgical Treatment of Moderate Ischemic Mitral Regurgitation. New England Journal of Medicine. 2014;371(23):2178-2188.

23. Guilherme L, Ramasawmy R, Kalil J. Rheumatic fever and rheumatic heart disease: genetics and pathogenesis. Scandinavian journal of immunology. 2007;66(2-3):199-207.

24. Ayoub EM. Resurgence of rheumatic fever in the United States. The changing picture of a preventable illness. Postgraduate medicine. 1992;92(3):133-136, 139-142.

25. Carapetis JR, Steer AC, Mulholland EK, Weber M. The global burden of group A streptococcal diseases. The Lancet. Infectious diseases. 2005;5(11):685-694.

26. Marijon E, Ou P, Celermajer DS, et al. Prevalence of rheumatic heart disease detected by echocardiographic screening. $N$ Engl J Med. 2007;357(5):470-476.

27. Essop MR, Nkomo VT. Rheumatic and nonrheumatic valvular heart disease: epidemiology, management, and prevention in Africa. Circulation. 2005;112(23):3584-3591.

28. Waller BF, Howard J, Fess S. Pathology of mitral valve stenosis and pure mitral regurgitation-Part I. Clinical cardiology. 1994;17(6): 330-336.

29. Waller BF, Howard J, Fess S. Pathology of mitral valve stenosis and pure mitral regurgitation-Part II. Clinical cardiology. 1994;17(7):395-402.

30. Chen FY, Cohn LH. Chapter 41. Mitral Valve Repair. In: Cohn LH, ed. Cardiac Surgery in the Adult, 4e. New York, NY: The McGraw-Hill Companies; 2012.

31. Davutoglu V, Celik A, Aksoy M. Contribution of selected serum inflammatory mediators to the progression of chronic rheumatic valve disease, subsequent valve calcification and NYHA functional class. J Heart Valve Dis. 2005;14(2):251-256.

32. Guilherme L, Cury P, Demarchi LM, et al. Rheumatic heart disease: proinflammatory cytokines play a role in the progression and maintenance of valvular lesions. The American journal of pathology. 2004;165(5):1583-1591.

33. Hugenholtz PG, Ryan TJ, Stein SW, Abelmann WH. The spectrum of pure mitral stenosis. Hemodynamic studies in relation to clinical disability. Am J Cardiol. 1962;10:773-784.

34. DiBardino DJ, ElBardissi AW, McClure RS, Razo-Vasquez OA, Kelly NE, Cohn LH. Four decades of experience with mitral valve repair: Analysis of differential indications, technical evolution, and long-term outcome. The Journal of Thoracic and Cardiovascular Surgery. 2010;139(1):76-84.

35. Butany J, Collins MJ, David TE. Ruptured synthetic expanded polytetrafluoroethylene chordae tendinae. Cardiovascular pathology: the official journal of the Society for Cardiovascular Pathology. 2004;13(3):182-184.

36. Farivar RS, Shernan SK, Cohn LH. Late rupture of polytetrafluoroethylene neochordae after mitral valve repair. J Thorac Cardiovasc Surg. 2009;137(2):504-506.

37. Rankin JS, Burrichter CA, Walton-Shirley MK, et al. Trends in mitral valve surgery: a single practice experience. J Heart Valve Dis. 2009;18(4):359-366.

38. Shahin GM, van der Heijden GJ, Kelder JC, Boulaksil M, Knaepen PJ, Six AJ. Long-term follow-up of mitral valve repair: a single-center experience. Medical science monitor : international medical journal of experimental and clinical research. 2006;12(7):Cr308-Cr314.

39. Zhang ZW, Gu TX, Xiu ZY. Management of mild aortic valve stenosis in rheumatic mitral surgery. J Thorac Cardiovasc Surg. 2014;148(6):3254-3255.

40. Yau TM, El-Ghoneimi YA, Armstrong S, Ivanov J, David TE. Mitral valve repair and replacement for rheumatic disease. JThorac Cardiovasc Surg. 2000;119(1):53-60. 
41. Wilson W, Taubert KA, Gewitz M, et al. Prevention of infective endocarditis: guidelines from the American Heart Association: a guideline from the American Heart Association Rheumatic Fever, Endocarditis, and Kawasaki Disease Committee, Council on Cardiovascular Disease in the Young, and the Council on Clinical Cardiology, Council on Cardiovascular Surgery and Anesthesia, and the Quality of Care and Outcomes Research Interdisciplinary Working Group. Circulation. 2007;116(15):1736-1754.

42. Dreyfus G, Serraf A, Jebara VA, et al. Valve repair in acute endocarditis. Ann Thorac Surg. 1990;49(5):706-711; discussion 712-703.

43. Mihaljevic T, Paul S, Leacche M, et al. Tailored surgical therapy for acute native mitral valve endocarditis. J Heart Valve Dis. 2004;13(2):210-216.

44. Ad N. Transient systolic anterior motion after mitral valve repair: does it affect long-term outcomes? J Thorac Cardiovasc Surg. 2015;149(2):477-478.

45. Brown ML, Abel MD, Click RL, et al. Systolic anterior motion after mitral valve repair: is surgical intervention necessary? J Thorac Cardiovasc Surg. 2007;133(1):136-143.

46. Maslow AD, Singh A. Mitral valve repair: to slide or not to slideprecardiopulmonary bypass echocardiogram examination. Journal of cardiothoracic and vascular anesthesia. 2006;20(6):842-846.

47. Lee KS, Stewart WJ, Lever HM, Underwood PL, Cosgrove DM. Mechanism of outflow tract obstruction causing failed mitral valve repair. Anterior displacement of leaflet coaptation. Circulation. 1993; 88(5 Pt 2):Ii24-Ii29.

48. Mihaileanu S, Marino JP, Chauvaud S, et al. Left ventricular outflow obstruction after mitral valve repair (Carpentier's technique). Proposed mechanisms of disease. Circulation. 1988;78(3 Pt 2):I78-I84.

49. Sherrid MV, Chaudhry FA, Swistel DG. Obstructive hypertrophic cardiomyopathy: echocardiography, pathophysiology, and the continuing evolution of surgery for obstruction. The Annals of Thoracic Surgery. $2003 ; 75(2): 620-632$.
50. Maslow AD, Regan MM, Haering JM, Johnson RG, Levine RA Echocardiographic predictors of left ventricular outflow tract obstruction and systolic anterior motion of the mitral valve after mitral valve reconstruction for myxomatous valve disease. Journal of the American College of Cardiology. 1999;34(7):2096-2104.

51. Brinster DR, Unic D, D'Ambra MN, Nathan N, Cohn LH. Midterm Results of the Edge-to-Edge Technique for Complex Mitral Valve Repair. The Annals of Thoracic Surgery. 2006;81(5):1612-1617.

52. Crescenzi G, Landoni G, Zangrillo A, et al. Management and decisionmaking strategy for systolic anterior motion after mitral valve repair J Thorac Cardiovasc Surg. 2009;137(2):320-325.

53. Ibrahim M, Rao C, Ashrafian H, Chaudhry U, Darzi A, Athanasiou T. Modern management of systolic anterior motion of the mitral valve. Eur J Cardiothorac Surg. 2012;41(6):1260-1270.

54. Loulmet DF, Yaffee DW, Ursomanno PA, et al. Systolic anterior motion of the mitral valve: a 30-year perspective. J Thorac Cardiovasc Surg. 2014;148(6):2787-2793.

55. Kuperstein R, Spiegelstein D, Rotem G, et al. Late clinical outcome of transient intraoperative systolic anterior motion post mitral valve repair. J Thorac Cardiovasc Surg. 2015;149(2):471-476.

56. Maisano F. The edge-to-edge technique: a simplified method to correct mitral insufficiency. European Journal of Cardio-Thoracic Surgery. 1998;13(3):240-246.

57. Myers PO, Khalpey Z, Maloney AM, Brinster DR, D’Ambra MN, Cohn LH. Edge-to-edge repair for prevention and treatment of mitral valve systolic anterior motion. The Journal of Thoracic and Cardiovascular Surgery. 2013;146(4):836-840.
Research Reports in Clinical Cardiology

\section{Publish your work in this journal}

Research Reports in Clinical Cardiology is an international, peerreviewed, open access journal publishing original research, reports, editorials, reviews and commentaries on all areas of cardiology in the clinic and laboratory. The manuscript management system is completely online and includes a very quick and fair peer-review system.

\section{Dovepress}

Visit http://www.dovepress.com/testimonials.php to read real quotes from published authors. 